\title{
High in the Hierarchy: How Vertical Location and Judgments of Leaders' Power are Interrelated
}

\author{
Steffen R. Giessner and Thomas W. Schubert
}

\begin{tabular}{|l|l|}
\hline \multicolumn{2}{|l|}{ ERIM REPORT SERIES RESEARCH IN MANAGEMENT } \\
\hline ERIM Report Series reference number & ERS-2007-021-ORG \\
\hline Publication & February 2007 \\
\hline Number of pages & 45 \\
\hline Persistent paper URL & \\
\hline Email address corresponding author & sgiessner@rsm.nl \\
\hline Address & Erasmus Research Institute of Management (ERIM) \\
& RSM Erasmus University / Erasmus School of Economics \\
& Erasmus Universiteit Rotterdam \\
& P.O.Box 1738 \\
& 3000 DR Rotterdam, The Netherlands \\
& Phone: + 31104081182 \\
& Fax: $\quad+31104089640$ \\
& Email: info@erim.eur.nl \\
& Internet: www.erim.eur.nl \\
\hline
\end{tabular}

Bibliographic data and classifications of all the ERIM reports are also available on the ERIM website: www.erim.eur.n 


\section{ERASMUS RESEARCH INSTITUTE OF MANAGEMENT}

\section{REPORT SERIES \\ RESEARCH IN MANAGEMENT}

\begin{tabular}{|c|c|}
\hline \multicolumn{2}{|c|}{ ABSTRACT AND KEYWORDS } \\
\hline Abstract & $\begin{array}{l}\text { Leadership implies power. We argue, from a social embodiment perspective, that thinking about } \\
\text { power involves mental simulations of vertical location. Three studies tested whether judgments } \\
\text { of leaders' power and information on a vertical location are interrelated. In Studies 1a-c, } \\
\text { participants judged a leader's power after being presented with, among other information, an } \\
\text { organization chart containing either a long or a short vertical line. A longer vertical line increased } \\
\text { judged power. Study } 2 \text { showed that this effect persists when longer (vs. shorter) vertical lines are } \\
\text { presented in an independent priming task and not in an organization chart, and that horizontal } \\
\text { lines do not have the same effect. Finally, Studies } 3 a \text { and } 3 \mathrm{~b} \text { showed the reverse causal effect: } \\
\text { Information about a leader's power influenced participants' vertical positioning of a leader's box } \\
\text { in an organization chart and of a leader picture into a team picture. Implications for leadership } \\
\text { communication are discussed. }\end{array}$ \\
\hline Free Keywords & Leadership, Power, Person perception, Embodiment, Metaphor \\
\hline Availability & $\begin{array}{l}\text { The ERIM Report Series is distributed through the following platforms: } \\
\text { Academic Repository at Erasmus University (DEAR), DEAR ERIM Series Portal } \\
\text { Social Science Research Network (SSRN), SSRN ERIM Series Webpage } \\
\text { Research Papers in Economics (REPEC), REPEC ERIM Series Webpage }\end{array}$ \\
\hline Classifications & $\begin{array}{l}\text { The electronic versions of the papers in the ERIM report Series contain bibliographic metadata } \\
\text { by the following classification systems: } \\
\text { Library of Congress Classification, (LCC) LCC Webpage } \\
\text { Journal of Economic Literature, (JEL), JEL Webpage } \\
\text { ACM Computing Classification System CCS Webpage } \\
\text { Inspec Classification scheme (ICS), ICS Webpage }\end{array}$ \\
\hline
\end{tabular}


Running Head: High in the Hierarchy

High in the Hierarchy: How Vertical Location and Judgments of Leaders' Power are Interrelated

\author{
Steffen R. Giessner
}

Erasmus Universiteit Rotterdam, The Netherlands

Thomas W. Schubert

Vrije Universiteit, Amsterdam

Steffen R. Giessner, Rotterdam School of Management, Erasmus University Rotterdam, The Netherlands; Thomas Schubert, Department of Social Psychology, Vrije Universiteit, Amsterdam, Netherlands.

The research reported in this article was supported by a fellowship from the Erasmus Research Institute of Management, Erasmus University Rotterdam, The Netherlands, awarded to the first author. We would like to thank John Schaubroeck, Diana Rus, and three anonymous reviewers for helpful comments on an earlier version of this manuscript. Furthermore, we thank Laurence Rook for the drawings in Figure 3.

Correspondence should be addressed to Steffen R. Giessner, RSM Erasmus University, Erasmus University Rotterdam, Room T8-44, P.O. Box 1738, 3000 DR Rotterdam, The Netherlands, Phone: 0031 (0) 10 4081572,FAX: 0031 (0) 10 4089015, e-mail: sgiessner@,rsm.nl. 
High in the Hierarchy: How Vertical Location and Judgments of Leaders' Power are Interrelated

\begin{abstract}
Leadership implies power. We argue, from a social embodiment perspective, that thinking about power involves mental simulations of vertical location. Three studies tested whether judgments of leaders' power and information on a vertical location are interrelated. In Studies 1a-c, participants judged a leader's power after being presented with, among other information, an organization chart containing either a long or a short vertical line. A longer vertical line increased judged power. Study 2 showed that this effect persists when longer (vs. shorter) vertical lines are presented in an independent priming task and not in an organization chart, and that horizontal lines do not have the same effect. Finally, Studies $3 \mathrm{a}$ and $3 \mathrm{~b}$ showed the reverse causal effect: Information about a leader's power influenced participants' vertical positioning of a leader's box in an organization chart and of a leader picture into a team picture. Implications for leadership communication are discussed.
\end{abstract}

Keywords: leadership, power, person perception, embodiment, metaphor 


\section{High in the Hierarchy: How Vertical Location and Judgments of Leaders' Power are}

\section{Interrelated}

Leaders often sit on the top floors of their companies' buildings, decide on housing their organizations in tall(er) buildings, and are more likely to hold a leading position if they are tall individuals. Research has for instance shown that taller persons earn higher wages, are more likely to be found in higher status occupations, and are more likely to win presidential elections (Stogedill, 1948; Young \& French, 1996; for an overview see Judge \& Cable, 2004). Hence, being "up" seems to be associated with holding power. We also use this vertical dimension in our language when we refer to power relations between individuals and especially between leaders and followers. For instance, leaders are thought of as having high status, they supervise their employees, and they are $u p$ in the organizational hierarchy. In contrast, employees are referred to as subordinates, and as being at the lower levels of a hierarchy. We even differentiate between managers as being top leaders versus non top leaders. In sum, we often use the metaphor of powerful = up when we talk about power.

Psychological definitions of power have identified the ability or capacity to influence others through the control over resources as the core of power (see Galinsky, Gruenfeld, \& Magee, 2003; Keltner, Gruenfeld, \& Anderson, 2003 for a more detailed discussion of the definitions of power). However, these definitions do not address the issue of how people mentally represent and understand power. In this paper, we propose that the ubiquitous environmental correlation between vertical position and power leads to the association of verticality and power, and the use of a mental representation of space for thinking about power.

The influence of spatial perceptions on power judgments about leaders is particularly relevant for leadership in the workplace, because the ability to influence followers is of central importance for effective leadership. Not only vertical size (i.e., physical height) of a leader might be perceived as a sign of power, but other external cues on a vertical dimension may also influence 
power perceptions of leaders (e.g., on which floor the office of a leader is; how high the picture of the leader hangs on a wall). Thus, leaders might be able to confirm or to manipulate others' power judgments about themselves by using such vertical positioning in space. In this article, we empirically demonstrate this relationship between displays of spatial information and judgments of leaders' power.

\section{Power, Leadership, and Physical Appearance}

The concepts of power and leadership are naturally related. However, they are not the same (Goodwin, 2003). Whereas power is defined as control over resources which provides a person with the ability to influence others (Galinsky et al., 2003; Keltner et al., 2003), leadership is defined as the process of influencing others (i.e., the followers) to contribute towards a common goal (Chemers, 2001). Hence, powerful persons are not necessarily leaders, but leadership implies and requires power (Goodwin, 2003).

To some extent, the physical appearance of potential leaders may determine whether they gain power or not. Leaders' height is one such variable that influences leaders' power. The interrelation of physical height and various workplace related variables has received tremendous research interest in psychology (see Judge \& Cable, 2004, for an overview). Empirical evidence indicates that physical height is positively related to higher job status (Egolf \& Corder, 1991; Melamed \& Bozionelos, 1992), higher salaries (Deck, 1968; Frieze, Olson, \& Good, 1990; Judge \& Cable, 2004; Melamed, 1994), and a higher probability of leader emergence (Higham \& Carment, 1992; Stogdill, 1948). In addition, research also indicates that more powerful persons are perceived as being taller (Dannenmaier \& Thumin, 1964; Wilson, 1968). A recent meta-analysis by Judge and Cable (2004) indicated that the physical height of persons in the workplace is related to social esteem (i.e., representing a measure of status within an organization), performance, and leader emergence. Thus, it seems that individuals' height is related to power in organizational settings. 
Why are taller persons evaluated as being more powerful, and why do they eventually become more powerful? Judge and Cable (2004) argued that evolutionary origins are responsible for this connection. Physical height is an index of strength, or as Freedman (1979) noted, "throughout nature the rule is the bigger, the more dangerous" (p. 29). In other words, it might have been an evolutionary advantage to interpret height as power. Beside the evolutionary perspective, there is also a social learning or developmental perspective. Size is especially an issue during childhood and adolescence. Children are confronted with taller parents who have power over them. Thus superiority in stature and parental dominance might become associated (Schwartz, Tesser, \& Powell, 1982). During adolescence taller children may often use their strength to physically coerce smaller children. Even in adulthood, taller people often use their physical advantage to gain power, or as Felson (2002) framed it: Big people hit little people. In sum, there are different reasons to explain why physical height is associated with power perceptions.

\section{Verticality and Power: A Social Embodiment Perspective}

These connections between vertical size and power might, however, be more deeply grounded in cognitive processes. People might not only use the physical size of a person to infer the power of this person, but develop a general association between vertical location and power. Judge and Cable (2004) already hinted in their argumentation to this fact. They stated that there is "a basic human perceptual bias whereby people expect a positive relationship between an entity's size and its value or status" (p. 429; see also Dannenmaier \& Thumin, 1964; Higham \& Carment, 1992). Supporting arguments for such a general relation between power and vertical location can be found in the work of Lakoff and Johnson (1980), who argued that we use metaphors like power = up as "metaphors we live by". They assume that this metaphor reflects that our cognitive system mentally represents concepts like control and power on an up-down dimension.

A similar argument is made by Fiske in his Relational Models Theory (Fiske, 1992, 2004). This theory proposes that one basic relational model underlying human relations is authority 
ranking, the structuring of interactions according to ordered differences. Authority ranking is the basis for status, rank, and hierarchies in organizations. Fiske (2004) argued that people mentally represent authority rankings primarily as differences in space, especially vertical differences and differences in size (and, in addition, force, front/back, and earlier/later).

Such a view is in line with theories of embodied cognition, which argue that people use perceptual content in their conceptual thinking (Barsalou, 1999; Glenberg, 1997). Recent reviews of the empirical evidence suggest that mental representations of concepts, even abstract ones, are indeed tied to their perceptual basis (Niedenthal, Barsalou, Winkielman, Kraut-Gruber, \& Ric, 2005). For instance, time is represented on a horizontal spatial dimension (Boroditsky \& Ramscar, 2002), valence is represented on a vertical dimension (Crawford, Ochsner, Drake, \& Murphy, in press; Meier \& Robinson, 2004), and communication is represented as movement towards and away from the body (Glenberg \& Kaschak, 2003). Similarly, power might be mentally represented by using the perceptual content of size and height: Thinking about power should imply thinking about vertical differences and positions in space. Recently, Schubert (2005) showed in a series of studies that this is indeed the case. For example, in one study, participants had to evaluate pairs of powerful and powerless groups represented by labels (e.g., employer-employee, master-servant, boss-staffer, and professor-student). One of the labels was presented on the top, the other at the bottom of a computer screen. The participants' task was to indicate which group label was powerful (or, in another condition, powerless) by pressing a key as quickly as possible. As predicted by the embodiment perspective, participants reacted faster when powerful and powerless groups were presented in the correct spatial position, that is, when powerful groups appeared on top and powerless groups appeared at the bottom. Further studies replicated this finding and revealed that this effect is not related to valence judgments; even negatively evaluated powerful groups were identified more accurately as representing powerful words when they were on top of the screen; the opposite being the case for negatively evaluated powerless groups. 
These lines of thinking converge on the hypothesis that leaders' power is mentally represented as spatial order on the vertical dimension. This thesis can explain the effect of individuals' height on power perceptions, but its implications go further. One immediate and interesting implication is that powerful persons or persons striving for power may represent themselves as high in real space, or associate themselves with high things. Thus, because of the association between height and power, power is not only mentally represented as height, but also externally presented and construed on the vertical dimension. Vertical displays may thus be used to constitute, confirm, communicate, or challenge power relations between leaders and followers (cf. Fiske, 2004).

\section{Overview of the Current Research}

In sum, there is theoretical reasoning as well as empirical evidence suggesting that thinking about power involves a mental simulation of a vertical space. Leadership implies power (Goodwin, 2003) and, therefore, thinking about leaders should also imply thinking about power. Consequently, taking an embodied view on cognition, power evaluations of leaders should be influenced by information pertaining to vertical location, even if this information is not directly tied to the leader's height. Such an effect has not been demonstrated yet: While the Schubert's studies (2005) showed the automaticity of using vertical location cues for power judgments, they did not show that the amount of power attributed to a group or person is influenced itself. Thus, it is still unclear whether only the fluency of a power judgment or its outcome can be influenced. We hypothesized that even seemingly meaningless information pertaining to different vertical locations can influence power judgments. The first goal of the current research was to show that power evaluations of leaders are themselves influenced by manipulating vertical locations.

The second goal was to demonstrate that the reverse is also true - that leaders' power is spontaneously externally represented on a vertical dimension. If both effects, that of perceived 
height on judgments and that of judgments on construed height, can be shown, we can demonstrate a closed circle between cognition and external representation.

The following six studies were designed to test these hypotheses. Studies 1a, 1b, and 1c used essentially the same paradigm. In all three studies, the manipulation consisted in varying the vertical difference between manager and subordinates in an organization chart. The goal of Study 1a was to test our hypothesis that this relatively meaningless information (line length is usually not interpreted in organization charts) influences judgments of leader power. Study $1 \mathrm{~b}$ replicated this effect by using a different sample, and with variations in the organization chart. Study 1c explores whether the relation between vertical location and power judgments generalizes to evaluations of leader charisma. Study 2 goes one step further by manipulating perceptions of vertical difference independently from information about the leader by introducing a priming of large vs. small vertical differences. In addition, Study 2 also tests whether the same results are found when horizontal difference is manipulated. Finally, Study $3 \mathrm{a}$ and $3 \mathrm{~b}$ address the reversed causal influence, namely, in how far information about a leader's power impacts on vertical positioning in space. In sum, our studies test how power judgments about a leader are influenced by contextual information on vertical location in space and vice versa.

\section{Study 1}

The first three studies manipulated arbitrary differences in vertical positions. The studies were framed as person perception tasks in which the participants had to estimate a leader's power after receiving little information about him (i.e., a male leader was used as target person). Part of this information was an organizational chart of the leader's organization. Because we hypothesized that power judgments of leaders would be influenced by seemingly meaningless information on a vertical dimension, we chose to manipulate the length of a line between the first and the second level in an organization chart and thereby the vertical difference between leader and followers. On the one hand, an organization chart represents relevant information for an organization and is often 
used to illustrate the organization's structure and the positions of its leading persons. On the other hand, the length of the lines between levels of an organization does not represent any canonically used information, because it does not change the structure of the organization chart. Therefore, our manipulation already shows the applicability in organizational contexts of seemingly meaningless information to evaluate a leader's power.

In Study 1a, the structure of the organization chart itself was the same in all conditions, only the length of the vertical line varied. In Study $1 \mathrm{~b}$ and 1c, we orthogonally manipulated the number of boxes at the lower level of the organization chart, in order to rule out that it is the sheer size of the chart that is driving the effect. Furthermore, we aimed to show that our main manipulation works with different layouts of the organization chart. Finally, in Study 1c, participants also had to evaluate the leader's charisma. We aimed to show that our manipulation does not elicit a general perception of "more" on any construct. We decided to look at evaluations of leader charisma, because charismatic leaders are assumed to have great referent power to influence their followers (Bass, 1985; Burns, 1978), and are able to motivate and inspire people, and, hence to convince and persuade followers (Bass, 1985; Conger \& Kanungo, 1987). Thus, charisma is a related construct, which still bears differences to power.

\section{Study $1 a$}

\section{Method}

Participants and design. Sixty-four economics and business administration students from the Erasmus University Rotterdam, the Netherlands, (39 female, 25 male) participated in this study. The study was part of a set of studies, all of which were unrelated to the current study. All participants received 10 Euros for their participation in all studies. The age of the participants varied between 17 and 25 years. A one factorial between-subjects design was used manipulating only the vertical difference (large vs. small). 
Procedure. Participants arrived at the laboratory and were seated in separate cubicles in which they were provided with all instructions and questions via a computer. The study was presented as a study about person perceptions. First, participants were informed that they were going to evaluate a manager of a company and that they would have to evaluate this manager with only very little information given beforehand. Subsequently, a short text and an organization chart of Manager A's company were shown. It was said that the organization chart represents the organization structure of company A, that employees of this company have an average income of 36.000 Euro per year and that 126 people are employed at the company. The organization chart consisted of two levels. At the lower level, five equal-sized boxes were presented. These boxes were connected by a horizontal line. In addition, a vertical line connected the middle box to one box at the upper level. This upper box was labeled "Manager A". Next to this box at the upper level, a small picture of the face of a middle-aged man wearing a suit was presented. We included the picture to make it easier for the participants to evaluate the manager. The length of the vertical line between the two levels of the organization chart served as the manipulation of vertical difference. Half of the participants received an organization chart where the line was rather short (i.e., ca. $2 \mathrm{~cm}$ ) whereas the other half of the participants received an organization chart where the line was rather long (i.e., ca. $7 \mathrm{~cm}$ ). The boxes themselves were about $2 \mathrm{~cm}$ high. The organization charts can be seen in Figure 1.

Dependent measures. After the manipulation, participants had to answer a scale measuring perceived leader power. The scale consisted of 5 items ("I think that Manager A is dominant."; "I think that Manager A has a strong leader personality."; "I think that Manager A is self-confident."; "I think that Manager A has a lot of control in the company."; "I think that Manager A holds a very high status within the company.”). Participants had to answer these statements on a 7-point scale ranging from 1 (= totally disagree) to 7 (= totally agree). The scale was sufficiently reliable with $\alpha=$ .72. Finally, participants had to answer some demographic questions regarding their gender and age. 
Results

Preliminary analyses indicated that participants' gender did not have any main or interactive effect on the dependent measure. Therefore, this factor was not included in the following analysis. The averaged leader power score was submitted to an independent-samples $t$-test. The analysis yielded the expected significant effect of vertical difference, $t(62)=2.20, p=.03, \eta^{2}=.07$. Participants in the large vertical difference condition perceived the leader as being more powerful $(M=5.01, S D=.60)$ than participants in the small vertical difference condition $(M=4.62, S D=$ $.81)$.

\section{Study $1 b$}

\section{Method}

Participants and design. Fifty people from Jena, Germany (16 female, 34 male) participated in this study in return for a chocolate bar. The age of the participants varied between 18 and 39 years. The questionnaires were handed out in front of a dinning hall at lunch-time. This study used a 2 (vertical difference: large vs. small) by 2 (number of boxes at lower level: three vs. five) betweensubjects design.

Procedure. Essentially the same paradigm as in Study 1a was used. However, the study was conducted by using questionnaires. Furthermore, half of the participants received an organization chart with three boxes at the lower level. The other half received an organization chart with five boxes at the lower level. Hence, the organizational structure was manipulated by the number of the boxes at the second level in the organization chart. As in Study 1a, half of the participants received an organization chart with a short line between the first and the second level. The other half of the participants received an organization chart with a long line between the first and the second level.

Dependent measures. Participants had to answer the same 5-item scale measuring perceived leader power as used in Study 1a, with the minor change that the scales ranged from -3 (= totally disagree) to 3 (= totally agree). To ease comparability with the other studies, we add 4 to the 
resulting average scores. The scale was sufficiently reliable with $\alpha=.74$. Finally, participants had to indicate gender and age.

Results

In preliminary analyses gender did not have any effect on the dependent measure and was therefore not included in the following analysis. The measure of leader power was submitted to a 2 (vertical dimension) x 2 (number of boxes) between-subjects ANOVA. Means and standard deviations are listed in Table 1. The analysis yielded a significant main effect of vertical difference, $F(1,46)=7.26, p=.01, \eta_{\mathrm{p}}^{2}=.14$. Participants in the large vertical difference condition perceived the leader as being more powerful $(M=5.63, S D=.77)$ than participants in the small vertical difference condition $(M=5.02, S D=.80)$. No other effect reached significance (both $F \mathrm{~S}<1.1)$.

\section{Study $1 c$}

\section{Method}

Participants and design. Ninety-four economics and business administration students from the Erasmus University Rotterdam, the Netherlands (32 female, 62 male) participated in this study. The age of the participants varied between 17 and 25 years. The study was part of a set of studies all of which were unrelated to the current study. All participants received 10 Euros for their participation in all studies. This study used a 2 (vertical difference: large vs. small) by 2 (number of boxes: three vs. five) between-subjects design.

Procedure. The same laboratory paradigm as in Study 1a was used. The manipulation of the vertical and horizontal dimension was exactly the same as in Study 1b. Participants were again randomly assigned to one of the four conditions.

Dependent measures. After the manipulations, participants had to answer the 5-item scale measuring perceived leader power as used in the previous studies. Furthermore, participants also had to answer a 3-item scale (see van Knippenberg \& van Knippenberg, 2005) measuring perceived leader charisma ("I think that Manager A is enthusiastic."; "I think that Manager A is inspiring."; "I 
think that Manager A could arouse a feeling of commitment among his employees.”). Participants had to answer all items on a 7-point scale ranging from 1 (= totally disagree) to 7 (= totally agree). The order of all eight items was randomized. A principal component analysis over all items using an orthogonal rotation yielded two factors explaining 69 per cent of the variance. All items of the leader power measure loaded on the first factor with factor loadings higher than .70 . All the items of the charisma scale loaded on the second factor with factor loadings higher than .78. Both scales were reliable (leader power: $\alpha=.83$; charisma: $\alpha=.80$ ). Therefore, we created average scores of both scales for further analyses. The measures of leader power and charisma were significantly correlated, $r(92)=.31, p=.003$. Finally, participants had to answer some demographic questions regarding their gender and age.

Results

Preliminary analyses indicated that gender of the participants did not have any main or interactive effect on the dependent measure and was therefore not included in the following analyses.

The measure of leader power was submitted to a 2 (vertical difference) x 2 (number of boxes) between-subjects ANOVA. Means and standard deviations are listed in Table 2. The analysis yielded a significant main effect of vertical difference, $F(1,90)=4.10, p=.046, \eta_{\mathrm{p}}{ }^{2}=.04$. Participants in the large vertical difference condition perceived the leader as being more powerful $(M=5.18, S D=.83)$ than participants in the small vertical difference condition $(M=4.81, S D=$ .91). No other main or interaction effect emerged (both $F_{\mathrm{s}}<1$ ).

The measure of charisma was submitted to a 2 (vertical difference) x 2 (number of boxes) between-subjects ANOVA (see Table 2 for means and standard deviations). This analysis yielded neither a significant effect of vertical difference, $F(1,90)=.24, p=.63, \eta_{\mathrm{p}}{ }^{2}<.01$, nor any other significant effect. 


\section{Discussion}

We predicted that seemingly meaningless contextual information on a vertical dimension in space can influence judgments of a leader's power. To show this, we manipulated the length of a line in an organization chart. As hypothesized, our manipulation had a significant influence on participants' evaluations of the leader's power. An organization chart having a longer vertical line between the first and the second level led participants to evaluate the leader as being more powerful as compared to an organization chart with a shorter line between the organization levels. The second manipulation, which we implemented on the horizontal dimension (Study $1 \mathrm{~b}$ and 1c), did not have an effect on leadership power perceptions. This indicates that the vertical position of the box alone caused the differences in the evaluation of a leader's power, and not the resulting increased size of the chart. Furthermore, this shows that our manipulation worked for different layouts of the organizational structure. Finally, Study 1c showed that our manipulation did have an impact on participants' evaluation of leader power and not on participants' perceptions of leader charisma. This shows that the increased vertical difference did not result in a general judgmental bias on every concept, as one could expect from the observation that "more" typically also equals up. The results were replicated with both a general German sample and Dutch business administration student samples.

\section{Study 2}

Although the results of Study 1 showed consistently that power judgments are influenced by seemingly meaningless information on a vertical dimension in space, an alternative explanation is possible: The effects we have found might be primarily effects of general distance (i.e., difference) and not necessarily effects of vertical difference. The paradigm used in Study 1 cannot rule this out because in an organization chart, the powerful are up and the powerless are down by convention. Study 2 aimed to disentangle vertical and horizontal difference by using a paradigm in which 
difference and dimension were independently manipulated. We expected that the manipulation of vertical difference, but not of horizontal difference, would affect power judgments.

The study was framed as a memory study in which participants had to learn information about a manager. Part of this information was related to power and the time provided to learn the information was restricted so that it was not possible to memorize all of the information correctly. After the learning phase and before the recall phase, participants had to work on a line-estimation task which represented our manipulation of difference and dimension. In this task, participants had to estimate the length of a line in comparison to a standard line. The lines were either presented vertically or horizontally (manipulation of dimension) and were either small lines or longer lines in comparison to a standard line (manipulation of difference). Subsequently, participants had to recall the power information learned in the memory task (dependent variable). We assumed that the memory task would activate the power concept and the use of a vertical dimension in space for its mental representation. Only if the line estimation task presents vertical lines, it should interact with the memorized power information. Thus, we expected that line estimations on a vertical dimension would influence power judgments in the recall phase more strongly than line estimations on a horizontal dimension.

\section{Method}

\section{Participants and Design}

One-hundred eighty-two economics and business administration students from the Erasmus University Rotterdam, the Netherlands (74 females, 108 males) participated in this study. The study was part of a set of studies all of which were unrelated to the current study. All participants received 10 Euros for their participation in all studies. The age of the participants varied between 18 and 28 years. A two factorial between-subjects design was used manipulating the dimension (vertical vs. horizontal) and the difference (large vs. small). 


\section{Procedure}

Participants arrived at the lab and were placed in separate computer cubicles. All instructions were given via the computer itself. The study was introduced as a memory task. It was explained that the participants would have to read some information about a manager. They would have one minute to learn the information given. Afterwards they would have to reproduce this information. Furthermore, we explained that between the learning and reproduction phase, they would have to work on another task so as to render the reproduction more difficult.

Next, all participants were presented with a text containing a substantial amount of information about the manager (see Appendix 1). We deliberately packed the text full with information so that it would be very difficult for the participants to memorize all of the information within one minute. Part of the information was about the manager's power. This information was disguised as a recent survey among employees and presented as percentages on six different dimensions. These dimensions represented the dimensions used in Study 1 to measure perceived leader power plus a dimension indicating directly leader power. This information was the focal point of interest in our study, because participants had to recall this information at the end of the experiment (i.e., dependent variable). After one minute, a seemingly unrelated task followed in which the independent variables were manipulated.

The following task implemented both manipulations. Participants had to estimate the length of various black lines (the target lines, 60 pixels wide) in comparison to a white standard line (60 pixels wide; 130 pixels long; screen resolution was 1024 x 768 pixels). Target line and standard line were presented next to each other. In the horizontal condition, participants saw the two lines going from the left to the right of the screen and had to estimate how much longer the target line was as compared to the standard line. In the vertical condition, participants saw the lines going from the bottom to the top of the screen and had to estimate how much taller the target line was as compared to the standard line. Participants had to estimate each of the 20 target lines separately. Half of the 
participants were shown very long/tall target lines (varying between lengths of 510 and 600 pixels), whereas the other participants were shown target lines of about the same length/height as the standard line (varying between lengths of 70 and160 pixels). This implemented the difference manipulation (large vs. small).

Subsequently, the recall task followed. Participants had to answer different questions regarding the information provided at the beginning. These measures served as our main dependent variables.

\section{Dependent Measures}

We recorded the estimated line lengths in the manipulation task. The 20 different estimations were averaged and served as a manipulation check for the difference manipulation.

Participants had to reproduce different pieces of the text about the manager after the line estimation task. First, they were asked to recall the percentages presented in the purported employee survey. We asked for each dimension directly and participants had to fill in the percentage in a box. The dimensions were presented in random order. We computed the deviations of the reproduced percentages from the original information and $z$-standardized these scores. The average of the $6 z$ scores served as a score of power misjudgement.

Next, people had to reproduce different information about the manager (i.e., "When was the company founded?"; "How many branches does the company have?"). These questions were not of focal interest for this study and analyses on these measures did not yield any significant results of our manipulations. Finally, some demographic questions followed.

\section{Results}

\section{Perceived Length of Lines}

For a check of the difference manipulation we submitted the average evaluation of the line lengths to a 2 (dimension) x 2 (difference) between-subjects ANOVA. This yielded only a significant effect of difference, $F(1,178)=101.57, p<.001, \eta_{\mathrm{p}}{ }^{2}=.36$. Participants in the large 
difference condition estimated the lines as being on average about 4.76 times longer/taller $(\mathrm{SD}=$ 3.68) than the standard line. In contrast, participants in the small difference condition estimated the lines as being on average about .81 times longer/taller $(\mathrm{SD}=.65)$ than the standard line.

\section{Power Misjudgement}

A 2 (dimension) x 2 (difference) between-subjects ANOVA on the measure of power misjudgement yielded a significant effect of difference, $F(1,178)=4.78, p=.03, \eta_{\mathrm{p}}{ }^{2}=.03$. Longer lines led to higher estimations on the power items, whereas shorter lines led to lower estimations on the power items. However, this main effect was qualified by a significant interaction, $F(1,178)=$ 4.46, $p=.04, \eta_{\mathrm{p}}{ }^{2}=.02$. Simple main effect analysis indicated that the difference manipulation had a significant effect when vertical lines were compared, $F(1,178)=9.14, p=.003, \eta_{\mathrm{p}}{ }^{2}=.05$. Participants in the vertical condition estimated the power items higher in the large difference condition $(\mathrm{M}=.13, \mathrm{SD}=.24)$ and lower in the small difference condition $(\mathrm{M}=-.21, \mathrm{SD}=.77)$. In contrast, there was no significant simple main effect within the horizontal condition, $F(1,178)=$ $.03, p=.96, \eta^{2}<.01$. The misjudgements were quite similar in the horizontal condition (large difference: $\mathrm{M}=.08, \mathrm{SD}=.42 ;$ small difference: $\mathrm{M}=.08, \mathrm{SD}=.55)$.

\section{Discussion}

The main goal of Study 2 was to show that vertical, but not horizontal difference influences power judgments. Therefore, we independently manipulated difference (i.e., length of lines in comparison to a standard line) and spatial dimension. As hypothesized, we found an interactive effect of our manipulations on participants' judgments of a leader's power. The difference between standard and comparison line (large vs. small) did not influence power judgments when the lines were presented horizontally on the screen, but it had an impact on power judgments when the lines were presented vertically on the screen. Comparing much larger vertical lines to a standard line led to higher estimates of the leader's power than comparing lines of about equal length. 
In addition to showing that vertical, but not horizontal information biases power judgments, this study also shows that the height information does not have to be directly related to or presented in conjunction with the leader. Rather, the recall of information about a leader was biased by information that was presented independently of the leader after the learning phase. Apparently, size differences can distort power differences that are held in memory at the same time. This confirms the hypothesis that the mental representation of power relies on spatial cognition.

\section{Study 3}

So far, we have shown how spatial information on a vertical dimension can affect others' judgments of leader power. Our basic argument was that power is thought about in terms of a vertical spatial dimension. If this is true, another hypothesis follows that reverses the causality shown in the previous studies: The activation of the concept of power (i.e., through the salience of the notion of a leader) should lead individuals to make use of a vertical dimension to represent power in space. In other words, there should not only be a causal link from the vertical dimension to power evaluations, but also from direct information about power to vertical positioning in space. Support for this hypothesis comes from studies showing that information about power does actually influence estimations of vertical size (i.e., height). For instance, Dannenmaier and Thumin (1964) let 46 freshmen in a nursing school estimate the height of four persons they knew well and who differed in their status. The students consistently overestimated the height of the high-status people, and underestimated the height of the low status people. In another study by Wilson (1968), the same person was introduced with a different academic status to five different groups of students. Afterwards, the student groups had to evaluate the height of the person. Again, academic status information influenced the height estimations of the student groups (i.e., the higher the status, the taller the person was judged to be). Extending these findings, and based on a social embodiment perspective on power, we predict that information about a person's power should also be reflected 
in the positioning of the person on a vertical dimension in space, because power is embodied in a vertical dimension in space.

We tested this hypothesis in Study 3. The paradigm we used was basically a reversal of the paradigm used in Study 1. We manipulated the description of a leader as being powerful or nonpowerful. Afterwards, a graphical measure was used to test the prediction. In Study 3a, participants had to place the box of a manager into an organization chart. Of course, in an organization chart boxes are typically arranged such that they are horizontally centered, making it perhaps unlikely that participants would vary the placement on the horizontal dimension. This allows the alternative interpretation that any vertical difference produced by the participants simply reflects social distance. In addition, an organization chart might mark the vertical dimension as a power dimension. To rule out these alternative explanations, in Study $3 b$ the organization chart frame was removed, and participants simply placed a picture of a leader into a picture containing the team members. In both studies, placement could vary both horizontally and vertically. Thus, we tested whether increased power leads to a higher placement, but not to a horizontally different placement, both when an organization chart context is present and when it is not.

In addition, in Study $3 \mathrm{a}$ we also manipulated the perspective participants could take. Individuals may not only use the vertical dimension to think about the power of others, they may also use this vertical dimension to think about their own power. Thus, leaders themselves may use the vertical dimension to display or to strengthen their power. In other words, both thinking about others' and thinking about one's own power should imply the use of a vertical dimension in space. To show this, participants had to take either a $3^{\text {rd }}$ person perspective or the $1^{\text {st }}$ person perspective in Study $3 a$. 
Study $3 a$

\section{Method}

Participants and design. One hundred fifty-nine economics and business administration students from the Erasmus University Rotterdam, the Netherlands (46 female, 113 male) participated in this study. The study was part of a set of studies, all of which were unrelated to the current study. All participants received 10 Euros for their participation in all studies. The age of the participants varied between 17 and 27 years. This study used a 2 (power: high vs. low) by 2 (perspective: first person vs. third person) between-subjects design.

Procedure. The study was conducted in a laboratory. Participants were placed in separate cubicles and received all instructions and measures via computer. The study was framed as a study on person perceptions. It was stated that the study was part of a more general research program on person perceptions and that in the current part of the study we were interested in manager perceptions. Furthermore, it was said that participants will only receive little information and will have to infer information on other aspects.

Next, participants were briefed on how to use the computer and on how to answer the questions. As our main dependent variable, we measured the placement of a box on the computer screen (see below). However, beforehand, we included a task to practice such a placement. This "balloon task" was part of the instructions about the usage of the computer for this study. We deliberately chose a task which is unrelated to power and, at the same time, provides the participants with the possibility to practice the placement of an object on the screen. Participants saw a picture of two children on the left/bottom corner of the screen and a balloon on the right/bottom corner of the screen. Their task was to simply imagine that the children had lost the balloon and to place it somewhere on the screen where they thought the balloon would best fit.

Afterwards, the manipulation of the perspective was implemented. Half of the participants were told that they would read a description of a manager whom they would have to evaluate later. 
The other half of the participants were asked to put themselves into the role of the manager described next. Subsequently, half of the participants received a description of a powerful leader and the other half received a description of a less powerful leader. The descriptions were given in the second or third person depending on the perspective manipulation (see Appendix 2). However, most of the information given was exactly the same. The leader was described as being the manager of a company with 126 employees with an average gross salary of 36.000 Euro. In the high power condition it was explicitly said that the manager can be described as very powerful in his / her organization. In contrast, in the low power condition it was explicitly said that manager can be described as having very little power in his / her organization. Next, the dependent variables were measured.

Dependent measures. After the manipulations, participants had to indicate whether the leader was described as powerful or non-powerful. This served as a manipulation check of the power manipulations. Next, participants were shown an organization chart of the company of the manager (see Figure 2). Three boxes were fixed in the middle of the lower part of the screen. One box, named "Manager A," was placed on the left/bottom corner of the screen. Each box was 120 pixels wide and 80 pixels high. The task of the participants was to move the manager box on the screen to a place in the organization chart which best represents the manager in his / her company. We measured the participants' movements (in pixels) on the vertical and horizontal dimension in the organization chart (i.e., $\mathrm{y}$ - and $\mathrm{x}$-axis). The measurement indicates the location of the manager box on the screen starting from the original position of the manager box. We refer to these measures as $y$-location and $x$-location.

We included again the 5-item scale of leader power as used in the previous study. The scales ranged from 1 (= totally disagree) to 7 (= totally agree). The order of the items was randomized. A principal component analysis over all items using an orthogonal rotation yielded one factor explaining $68 \%$ of the variance. The scale was highly reliable $(\alpha=.95)$. Therefore, we 
created average scores for the further analyses. We used the power scale in this study to validate that our leader power measure did actually measure leader power perceptions, because in this study we explicitly manipulated power. Finally, participants had to answer some demographic questions regarding their gender and age.

Results

Preliminary analyses indicated again that gender of the participants did not have any main or interactive effect on the dependent measure. Therefore we did not include gender in the following analyses. Two participants were excluded from further analyses, because they failed to indicate the appropriate condition on the power manipulation check.

Movement of box. We conducted a 2 (power) x 2 (perspective) x 2 (location dimension: y vs. x) GLM with repeated measures on the last factor. The means and standard deviations are listed in Table 3. The analysis yielded a significant main effect of power, $F(1,153)=3.80, p=.05, \eta_{\mathrm{p}}{ }^{2}=$ .02 , and a significant main effect of location dimension, $F(1,153)=1246.90, p<.001, \eta_{\mathrm{p}}{ }^{2}=.89$. However, these main effects were qualified by the expected power by location dimension interaction, $F(1,153)=18.50, p<.001, \eta_{\mathrm{p}}{ }^{2}=.11$. No other significant main or interaction effects emerged from this analysis. To explain the interaction, we conducted a simple main effect analysis with the location measures. Power had a significant effect on the y-location (i.e., the vertical placement of the box), $F(1,153)=26.01, p<.001, \eta_{\mathrm{p}}{ }^{2}=.15$. Participants in the high power condition placed the manager box higher $(M=128.76, S D=121.72)$ than participants in the low power condition $(M=44.71, S D=65.32)$. There was no effect on the x-location, $F(1,153)=1.57, p$ $=.21, \eta_{\mathrm{p}}{ }^{2}=.01$. Thus, there was no difference in placing the manager-box on the horizontal dimension between the power conditions. All participants placed the box around the middle of the screen (above the middle box of the fixed boxes - see Figure 2).

Leader power perceptions. The measure of leader power was submitted to a 2 (power) $\mathrm{x} 2$ (perspective) between-subjects ANOVA (see Table 3 for means and standard deviations). The 
analysis yielded a significant main effect of power, $F(1,153)=560.95, p<.001, \eta_{\mathrm{p}}{ }^{2}=.79$. Participants in the high power condition perceived the leader as being more powerful $(M=5.84, S D$ $=.71)$ than participants in the low power condition $(M=2.86, S D=.85)$. No other main or independent effect emerged (both $F \mathrm{~s}<1.1$ ). Furthermore, leader power was significantly correlated with the $y$-location measure, $r(155)=.39, p<.001$, but not with the $\mathrm{x}$-location measure, $r(155)=$ $.10, p=.23$.

\section{Study $3 b$}

\section{Method}

Participants and design. Forty-eight students from the Erasmus University Rotterdam, and from the Hogeschool Rotterdam, the Netherlands (20 female, 28 male) participated in this study. The study was part of a set of studies all of which were unrelated to the current study. All participants received 10 Euros for their participation in all studies. The age of the participants varied between 18 and 28 years. This study used a one factorial between-subjects design manipulating power of the leader (high vs. low).

Procedure. The procedure followed the one of Study 3a with only a few changes. First, we only manipulated power of the leader. Second, the person to be evaluated was described as a leader and not as a manager in this study. Finally, all participants had to take a $3^{\text {rd }}$ person perspective.

Dependent measures. As in Study 3a, we included again the "balloon task" to familiarize participants with the placing task. After the manipulation, participants had to indicate whether the leader was described as powerful or non-powerful. All participants indicated the appropriate power condition on this test. Next, participants were shown a group of 6 people representing the team of the leader. Their pictures were little drawings ordered in a circle and placed in the middle of the screen. The pictures showed the upper part of the body and the persons wore casual clothes. One additional picture was placed on the left/bottom corner of the screen and described as being the picture of the leader. The task of the participants was to move the leader picture on the screen to a 
place which would best represent the relation of the leader to his followers (i.e., only the leader picture could be moved on the screen). Again, we measured the participants' movements (in pixels) on the vertical and horizontal dimension in the organization chart (i.e., $y$ - and $x$-axis). We refer to these measures as $y$-location and $x$-location.

We included again the 5-item scale of leader power as used in the previous study. Additionally, we included a sixth item (i.e., "I think that this is a powerful leader."), to get an even more direct measure of the concept. The items were randomized and ranged from 1 (= totally disagree) to 7 (= totally agree). A principal component analysis over all six items yielded one factor explaining 76 per cent of the variance. The scale was highly reliable $(\alpha=.94)$. Therefore, we created an average score of leader power perceptions for further analyses. Finally, participants had to answer some demographic questions regarding their gender and age.

\section{Results}

Preliminary analyses indicated again that participants' gender did not have any main or interactive effect on the dependent measure. Therefore, we did not include gender in the following analyses.

Picture movement. We conducted a 2 (power) x 2 (location dimension) GLM with repeated measures on the second factor. The analysis yielded a significant main effect of power, $F(1,46)=$ $8.66, p=.005, \eta_{\mathrm{p}}{ }^{2}=.16$, and a significant main effect of location dimension, $F(1,46)=972.49, p<$ $.001, \eta_{\mathrm{p}}{ }^{2}=.96$. However, these main effects were qualified by the expected power by location dimension interaction, $F(1,46)=7.41, p=.009, \eta_{\mathrm{p}}{ }^{2}=.14$. To explain the interaction, we conducted a simple main effect analysis for both dimensions. Power had a significant effect on the y-location (i.e., the vertical placement of the box), $F(1,46)=15.42, p<.001, \eta_{\mathrm{p}}{ }^{2}=.25$. Participants in the high power condition placed the leader picture higher $(M=335.00, S D=97.36)$ than participants in the low power condition $(M=210.08, S D=121.60)$. There was no effect on the placement of the box along the $\mathrm{x}$ dimension, $F(1,46)=.07, p=.79, \eta_{\mathrm{p}}{ }^{2}<01$. Thus, participants placed the picture at 
about the same position horizontally in both power conditions (high power: $M=392.71, S D=$ 62.52; low power: $M=400.79, S D=135.78$ ). Interestingly, the box of the leader was moved (on average) into the circle of the group members within the low power condition, and moved above the circle of group members within the high power condition.

Leader power perceptions. An independent sample $t$-test on the power scale yielded a significant effect of the power manipulation, $t(46)=9.18, p<.001, \eta^{2}=.65$. Participants in the high power condition perceived the leader as being more powerful $(M=5.64, S D=.79)$ than participants in the low power condition $(M=3.19, S D=1.04)$. Furthermore, the leader power measure was significantly correlated with the y-location, $r(46)=.47, p=.001$, but not with the $\mathrm{x}$-location, $r(48)$ $=.16, p=.27$.

\section{Discussion}

The goal of Study 3 was to show that information about a leader's power influences vertical positioning in space to represent this power. To test this, we reversed the paradigm used in Study 1. Participants received direct information about the power of a leader. Afterwards, participants had to place a box of the manager into an organization chart. The results of Study 3a showed that the description of a powerful leader led participants to place the box in the organization chart significantly higher as compared to the description of a non-powerful leader. Furthermore, the perspective participants took did not influence this effect. Thus, thinking about one's own power involves as much a schematization of vertical positions in space as thinking about another person's power.

The results of Study $3 \mathrm{~b}$ confirmed the effects of power on vertical positioning in a different graphical measure - the positioning of a leader picture in relation to the pictures of the leaders' group members (ordered in a circle). An important difference between the main dependent measures of Studies $3 \mathrm{a}$ and $3 \mathrm{~b}$ is that an organization chart (1) perhaps restricts the horizontal placement of boxes, and (2) marks the vertical dimension as reflecting power. Thus, the results of 
Study 3a can be alternatively interpreted as a difference effect, showing that powerful persons are distanced more from followers than powerless persons. However, Study $3 b$ showed that even when the vertical dimension is not especially marked by the context, and when the framing is not one that might restrict movement to the vertical dimension, power is indeed expressed as a vertical difference and not as a horizontal one.

The measure of perceived leader power was significantly influenced by the power manipulation. Furthermore, it was also significantly correlated with the graphical measure on the vertical dimension, which indirectly replicates the results from Study 1. In Study 3b, we added an item to the power scale directly measuring perceived power of the leader. This item loaded on the same factor as the other items. Therefore, Study 3 confirmed that the power scale we used throughout this research is a valid measure of perceived leader power.

In sum, the results of this study indicate that verbal information about power is expressed on the vertical dimension in space both spontaneously and in the formalized context of an organization chart. Larger power differences are visualized as larger vertical differences.

\section{General Discussion}

In a series of studies, we have shown that evaluations of a leader's power can be influenced by information about vertical positioning in space and that people represent information about a leader's power on vertical positions in space. Study 1 showed that judgments about a leader's power were influenced by arbitrary information on a vertical dimension in space (i.e., the length of a line in an organization chart). In addition, Study 1 showed that these effects mainly hold for power evaluations but not for charisma evaluations. Furthermore, we found these effects in German as well as Dutch samples and with different layouts of organizational structure. Because the results of Study 1 could be attributed to pure distance instead of vertical difference, Study 2 disentangled the effects of dimension and difference. This study showed that after activation of the concept "power", information on the vertical spatial dimension can influence power judgments of a powerful person. 
The study confirmed that it is primarily the vertical dimension and not the horizontal dimension that influences power judgments. Finally, Study 3 showed that participants spontaneously visualize information given about a leader's power on vertical positions in space (i.e., placement of the leader's box in an organization chart; and placement of a leader picture into a team picture). In addition, the last study indicated that these effects were independent of the perspective taken by the participants (i.e., $1^{\text {st }}$ or $3^{\text {rd }}$ person perspective).

Taken together, our research extends previous research by Schubert (2005), by showing for the first time how power judgments and information on a vertical dimension in space interrelate even when the spatial information is not directly tied to power, such as physical height,. More broadly, the results are relevant for various theoretical approaches. First, they support an embodied view on cognition (Barsalou, 1999; Glenberg, 1997), because the modality of space influenced judgments about power and vice versa. Since these effects occurred without conscious inferences or conscious metaphoric thinking, these results support the view that power is mentally represented on a spatial dimension. Second, our findings extend the research on the effects of physical height on power perceptions (Egolf \& Corder, 1991; Judge \& Cable, 2004; Melamed \& Bozionelos, 1992; Wilson, 1968). This research line has already shown how information about the vertical size of persons (i.e., height) can influence power perceptions in various contexts (cf. Judge \& Cable, 2004). We argued and showed that even more subtle information on this up-down dimension (i.e., not even necessarily related to an entity's physical power) can affect power evaluations of leaders and vice versa, because the concept of power is schematized on a vertical dimension in space. Third, Fiske's (1992, 2004) Relational Models Theory is particularly relevant for the current results. Fiske argues that vertical order in space is used to establish, communicate, mentally represent, confirm, and end authority relations. Our results represent a direct test of Fiske's (2004) theory by showing that displays of arbitrary information about vertical difference are both created to show and interpreted as showing power differences. 


\section{Implications}

The schematization of power has impressive consequences, as has been shown by the research on the impact of physical height on social esteem, performance and leadership emergence (Judge \& Cable, 2004). The relation between power and vertical dimension in space is, however, not only evident in this example. Society also provides us with diverse information indicating that the powerful is up and the powerless is down (Schubert, 2005). For example athletes are standing on top of a podium if they win their competitions, organizations build tall buildings to represent their power and economical success, financial market indices' going up and down is interpreted as power, and charts (e.g., music, book, soccer, business rankings) are ordered vertically with the best being on top. These cultural "habits" might be at the same time (1) products of the schematization of the vertical dimension in space into the power concept and (2) forces to create such a schematization. Thus, the schematization of power on a vertical dimension in space seems to already have a tremendous impact in our daily life.

The current findings may, however, have further practical implications. Although the studies were designed in a quite simple way, they already indicate how easily power judgments of leaders can be influenced by rather meaningless information. Given that powerful equals up, we might assume that various other information on a vertical dimension may influence power evaluations. For instance, the leader might have his / her office on the $26^{\text {th }}$ floor or on the $9^{\text {th }}$ floor, the leader might talk to his / her employees from a podium or not, and pictures of the leaders can be placed on top or on the bottom of a leaflet of an organization. All of this might lead people to judge the power of a leader differently. Similarly, the angle a picture is taken from could be an important issue. We might expect that a picture taken from below is perceived as being more powerful than a picture taken from above. The decision how to take and place a picture of a leader might be important for the external and internal communication process. Future research might address these applications. 


\section{The Multiple Meanings of Verticality}

The vertical dimension in space is certainly not the only schematization of the abstract concept of power (see Fiske, 2004; Schubert \& Waldzus, 2005). Power is, for instance, also related to bodily experiences like gestures of bodily force. Schubert (2004) showed in a series of studies that making a fist activates the concept of power for male participants. In other words, the concept of power is schematized in certain bodily gestures similar to the present results on the vertical dimension in space.

In addition, the vertical dimension in space is not only related to power. As Lakoff and Johnson (1980) already pointed out, different abstract concepts can be related to the same spatial dimension. There is, for example, converging evidence that a vertical dimension in space is also related to affective experiences and valence judgments (Crawford, Ochsner, Drake, \& Murphy, in press; Meier \& Robinson, 2004; 2005). Thus, individuals think of valence in terms of positive = up and negative $=$ down. This connection, however, does not explain the relation of power with vertical space found in the current research. Lakoff and Johnson argued that depending on the activation of the concept (i.e., metaphor), the corresponding spatial dimension will be activated. This was confirmed in one of the studies presented by Schubert (2005). In this study, either the concept of valence or the concept of power had to be judged. The vertical dimension in space was used for whatever concept was activated. Importantly, valence did not have an effect on vertical power ordering once power was activated. This study ruled out that the relation between power and verticality merely hinges on a confound of power and valence. Likewise, the procedures used in the present studies all activated the concept of power more or less directly before participants saw or produced vertical difference. Thus, the procedures assured that power and not valence was associated with the vertical dimension. 


\section{Caveats and Coda}

Of course, the present research is not without its limitations and raises a number of new questions. First, all studies relied on student samples. This should not be considered problematic for experimental studies that are aimed at establishing relationships with high internal validity, and there is no reason to expect students to behave differently from other populations (Brown \& Lord, 1999; Dipboye, 1990; Wofford, 1999). Furthermore, in five studies the participants were business school students and the majority had been working at least part-time in a business context. Still, it would be valuable to test for these effects in applied settings. Second, our research mainly focused on showing that information on a vertical dimension in space can influence power judgments and vice versa. Therefore, we used very artificial studies with manipulations focused to show this relation. Thus, it might be premature to conclude from these studies that these effects translate into natural contexts. However, as already discussed, our world is full of vivid examples of such a connection. Our theoretical account might provide a parsimonious framework to explain these examples. A final caveat relates to our focus on leader perceptions. Except for Study $3 b$, the target person in all studies was described as a manager. There is an ongoing controversy about the difference between leaders and managers (see Yukl, 2001). However, this controversy is mainly about differences in values, ideals, or behavior, and can be perceived on a more theoretical than empirical level. In addition, there is a common perception that both managers and leaders are powerful persons. Thus, for our research purposes, we think that this differentiation is not relevant. Indeed, Study $3 \mathrm{~b}$ showed that the same effects evolved when we described the target person as a leader. Furthermore, we always described the target person as being the manager of a company which normally involves leadership skills.

In conclusion, power judgments about powerful persons such as leaders and managers are not only influenced by the degree of control the persons have over resources to influence others. Very subtle and seemingly meaningless information on spatial location can bias power judgments 
about leaders and managers and vice versa. Because leaders and managers are naturally associated with power, it is important to know what kinds of perceptions influence these power judgments. An embodied view on cognition provides new and interesting hypotheses in this regard. 


\section{References}

Barsalou, L. W. (1999). Perceptual symbol systems. Behavioral and Brain Sciences, 22, 577-609.

Bass, B. M. (1985). Leadership and performance beyond expectations. New York: Free Press.

Boroditsky, L. \& Ramscar, M. (2002). The roles of body and mind in abstract thought. Psychological Science, 13, 185-189.

Brown, D. J., \& Lord, R. G. (1999). The utility of experimental research in the study of transformational/charismatic leadership. The Leadership Quarterly, 10, 531-539.

Burns, J. M. (1978). Leadership. New York: Harper \& Row.

Chemers, M. M. (2001). Leadership effectiveness: An integrative review. In M. A. Hogg \& R. S. Tindale (Eds.), Blackwell handbook of social psychology: Group processes (pp. 376-399). Oxford, UK: Blackwell.

Conger, J. A., \& Kanungo, R. N. (1987). Towards a behavioral theory of charismatic leadership in organizational settings. Academy of Management Review, 12, 637-647.

Crawford, L. E., Ochsner, S. M., Drake, J. T., \& Murphy, M. E. (in press). Emotions bias memory for location: Evidence for the spatial representation of affect. Cognition and Emotion.

Dannenmaier, W. D., \& Thumin, F. J. (1964). Authority status as a factor in perceptual distortion of size. Journal of Social Psychology, 63, 361-365.

Deck, L. P. (1968). Buying brains by the inch. Journal of the College and University Personnel Association, 19, 33-37.

Dipboye, R. L. (1990). Laboratory vs. field research in industrial and organizational psychology. In C. L. Cooper \& I. T. Robertson (Eds.), International review of industrial and organizational psychology (Vol. 5, pp. 1-34). Chichester, United Kingdom: Wiley.

Egolf, D. B., \& Corder, L. E. (1991). Height differences of low and high job status, female and male corporate employees. Sex Roles, 24, 365-373. 
Felson, R. B. (2002). Violence \& gender reexamined. Washington, DC: American Psychological Association.

Fiske, A. P. (1992). The four elementary forms of sociality: Framework for a unified theory of social relations. Psychological Review, 99, 689-723.

Fiske, A. P. (2004). Four modes of constituting relationships: Consubstantial assimilation; space, magnitude, time, and force; concrete procedures; abstract symbolism. In N. Haslam (Ed.), Relational Models Theory. A contemporary overview (pp. 61-146). Mahwah, NJ: Lawrence Erlbaum Associates.

Freedman, D.G. (1979). Human sociobiology. New York: Free Press.

Frieze, I. H., Olson, J. E., \& Good, D. C. (1990). Perceived and actual discrimination in the salaries of male and female managers. Journal of Applied Social Psychology, 20, 46-67.

Galinsky, A.D., \& Gruenfeld, D.H., \& Magee, J.C. (2003). From power to action. Journal of Personality and Social Psychology, 85, 453-466.

Glenberg, A. M. (1997). What memory is for. Behavioral and Brain Sciences, 20, 1-55.

Glenberg, A. M., \& Kaschak, M. P. (2003). Grounding language in action. Psychonomic Bulletin \& Review, 9, 558-565.

Goodwin, S.A. (2003). Power and prejudice: A social-cognitive perspective on power and leadership. In D. van Knippenberg \& M. A. Hogg (eds.), Leadership and power. Identity processes in groups and organizations (pp.138-152). Thousand Oaks, CA: Sage Publications.

Higham, P. A., \& Carment, W. D. (1992). The rise and fall of politicians: The judged heights of Broadbent, Mulroney and Turner before and after the 1988 Canadian federal election. Canadian Journal of Behavioral Science, 24, 404-409. 
Judge, T. A., \& Cable, D. M. (2004). The Effect of Physical Height on Workplace Success and Income: Preliminary Test of a Theoretical Model. Journal of Applied Psychology, 89, 428441.

Keltner, D., Gruenfeld, D.H., \& Anderson, C. (2003). Power, approach, and inhibition. Psychological Review, 110, 265-284.

Lakoff, G., \& Johnson, M. (1980). Metaphors we live by. Chicago and London: The University of Chicago Press.

Meier, B. P., \& Robinson, M. D. (2004). Why the sunny side is up. Psychological Science, 15, 243247.

Meier, B. P., \& Robinson, M. D. (2005). The metaphorical representation of affect. Methapher and Symbol, 20, 239-257.

Melamed, T. (1994). Correlates of physical features: Some gender differences. Personality and Individual Differences, 17, 689-691.

Melamed, T., \& Bozionelos, N. (1992). Managerial promotion and height. Psychological Reports, 71, 979-986.

Niedenthal, P., Barsalou, L. W., Winkielman, P., Kraut-Gruber, S., \& Ric, F. (2005). Embodiment in attitudes, social perception, and emotion. Personality and Social Psychology Review, 9, 184-211.

Schubert, T. W. (2004). The power in your hand: Gender differences in bodily feedback from making a fist. Personality and Social Psychology Bulletin, 30, 757-769.

Schubert, T. W. (2005). Your highness: Vertical positions as perceptual symbols of power. Journal of Personality and Social Psychology, 89, 1-21.

Schubert, T. W., \& Waldzus, S. (2005). Perceptual symbols of social relations: The uncontrollability of equating power and size. Manuscript submitted for publication. 
Schwartz, B., Tesser, A., \& Powell, E. (1982). Dominance cues in non-verbal behavior. Social Psychology Quarterly, 45, 114-120.

Stogedill, R.M., (1948). Personal factors associated with leadership: A survey of the literature. Journal of Psychology, 25, 35-71.

van Knippenberg, B. \& van Knippenberg, D. (2005). Leader self-sacrifice and leadership effectiveness: The moderating role of leader prototypicality. Journal of Applied Psychology, $90,25-37$.

Wilson, P. R. (1968). Perceptual distortion of height as a function of ascribed academic status. Journal of Social Psychology, 74, 97-102.

Wofford, J. (1999). Laboratory research on charismatic leadership: Fruitful or futile. The Leadership Quarterly, 10, 523-529.

Young, T.J., \& French, L.A. (1996). Height and perceived competence of U.S. Presidents. Perceptual and Motor Skills, 82, 1002.

Yukl, G. (2001). Leadership in organizations ( $5^{\text {th }}$ ed.). New York: Prentice Hall. 


\section{Appendix 1}

Mister X is manager of a small-sized company in France. The company has 212 employees and was founded in 1934. The company was actually founded by the grandfather of Mister X and deals with sport clothes. The grandfather of Mister X started with only 4 employees in a small house.

Nowadays the company has 11 branches in France, 2 branches in the Netherlands, and 1 branch in Spain.

A recent survey among the employees in his company revealed the following results:

$62 \%$ think that Manager $\mathrm{X}$ is dominant

$58 \%$ think that Manager X is self-confident

$71 \%$ think that Manager $\mathrm{X}$ has a very high status within the company

$52 \%$ think that Manager $\mathrm{X}$ is a strong leader

$72 \%$ think that Manager $\mathrm{X}$ has a lot of control in the company

$69 \%$ think that Manager $\mathrm{X}$ is powerful.

Manager $\mathrm{X}$ is now 43 years old. He has two sons in the age of 12 and 5. He studied management at the INSEAD University in Paris. Manager X is $182 \mathrm{~cm}$ tall, has brown hair and earns about 220.000 Euro a year. He likes Italian food and he can play the piano. 
Appendix 2

Manipulation of power $-1^{\text {st }}$ person perspective (Study $3 a$ )

High power

You are the manager of a company employing 126 employees. The average gross salary of the employees of company A is about 36.000 Euro. You can be described as very powerful within the company.

\section{Low Power}

You are the manager of a company employing 126 employees. The average gross salary of the employees of company A is about 36.000 Euro. You can be described as having very low power within the company.

Manipulation of power $-3^{\text {rd }}$ person perspective (Study $3 a \& 3 b$ )

High power

Manager $\mathrm{A}$ is the manager of a company employing 126 employees. The average gross salary of the employees of company A is about 36.000 Euro. Manager A can be described as very powerful within the company.

\section{Low Power}

Manager $\mathrm{A}$ is the manager of a company employing 126 employees. The average gross salary of the employees of company A is about 36.000 Euro. Manager A can be described as having very low power within the company. 
Table 1

Ratings of Leader Power (Study 1b).

\begin{tabular}{lcccc}
\hline & \multicolumn{3}{c}{ Vertical Difference } \\
\cline { 2 - 5 } & \multicolumn{3}{c}{ Small } & \multicolumn{2}{c}{ Large } \\
\cline { 2 - 5 } Number of boxes & $\mathrm{M}$ & $\mathrm{SD}$ & $\mathrm{M}$ & $\mathrm{SD}$ \\
\cline { 2 - 5 } & 5.25 & .91 & 5.62 & .70 \\
Three & & & 5.64 & .86 \\
\hline
\end{tabular}

Note. Scale ranges from 1 ( = low leader power) to 7 ( = strong leader power). 
Table 2

Ratings of Leader Power and Charisma (Study 1c).

\begin{tabular}{|c|c|c|c|c|c|}
\hline \multirow[b]{3}{*}{ Measure } & \multirow[b]{3}{*}{ Number of boxes } & \multicolumn{4}{|c|}{ Vertical Difference } \\
\hline & & \multicolumn{2}{|c|}{ Small } & \multicolumn{2}{|c|}{ Large } \\
\hline & & M & SD & $\mathrm{M}$ & SD \\
\hline \multirow[t]{2}{*}{ Leader power } & Three & 4.75 & .78 & 5.16 & .92 \\
\hline & Five & 4.84 & .97 & 5.21 & .73 \\
\hline \multirow[t]{2}{*}{ Charisma } & Three & 5.00 & .86 & 5.07 & .82 \\
\hline & Five & 5.27 & .76 & 5.37 & 1.01 \\
\hline
\end{tabular}

Note. Leader power and leader charisma were measured on a 7-point scale ranging from 1 ( = low leader power; low charisma) to 7 ( = strong leader power; strong charisma). 
Table 3

Movement of the Box in the Organization Chart and Ratings of Leader Power (Study 3a).

\begin{tabular}{|c|c|c|c|c|c|}
\hline \multirow[b]{3}{*}{ Measure } & \multirow[b]{3}{*}{ Perspective } & \multicolumn{4}{|c|}{ Leader Power } \\
\hline & & \multicolumn{2}{|c|}{ Low } & \multicolumn{2}{|c|}{ High } \\
\hline & & M & SD & M & SD \\
\hline \multirow[t]{2}{*}{ Y-location } & $3^{\text {rd }}$ person & 50.51 & 71.45 & 134.57 & 116.22 \\
\hline & $1^{\text {st }}$ person & 37.42 & 56.99 & 120.53 & 130.34 \\
\hline \multirow[t]{2}{*}{ X-location } & $3^{\text {rd }}$ person & 378.21 & 121.33 & 391.59 & 123.58 \\
\hline & $1^{\text {st }}$ person & 334.03 & 163.04 & 375.50 & 137.66 \\
\hline \multirow[t]{2}{*}{ Leader power } & $3^{\text {rd }}$ person & 2.81 & .84 & 5.78 & .69 \\
\hline & $1^{\text {st }}$ person & 2.92 & .86 & 5.92 & .73 \\
\hline
\end{tabular}

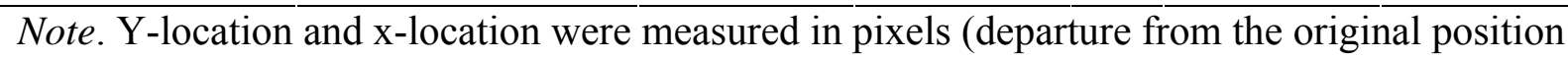
of the box on the screen). Leader power was measured on a 7-point scale ranging from 1 ( = low leader power) to 7 ( = strong leader power). 


\section{Figure Captions}

Figure 1. Pictures of the organization charts as used in Study 1 (5 boxes).

Figure 2. Screen Layout of Study 3 a.

Figure 3. Screen Layout of Study 3b. 
High in the Hierarchy 43

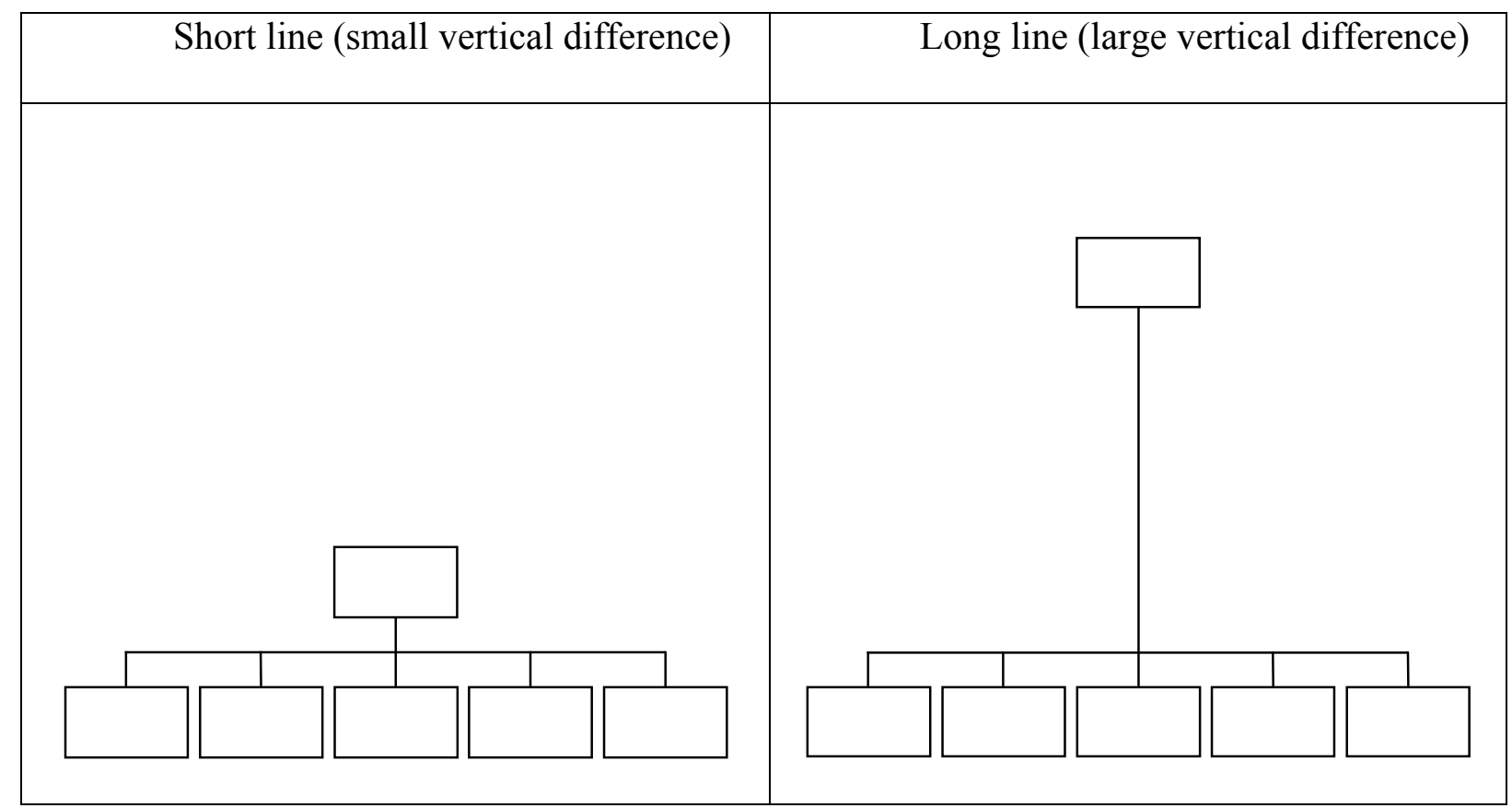


Here you can see an organization chart of Organization A. An organization chart is a simple figure representing the structure of an organization. In the left bottom corner is the box representing Manager A. Place the box representing Manager A on a position on the screen, which you think best represents the Manager's place in the organization chart (use the mouse to move the manager box). Press the "continue" button once you have placed the box.
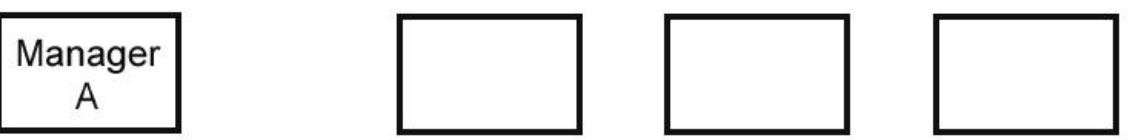

Continue

Note. The original text-material used in Study 3a was in Dutch. The participants had to move the box on the left bottom corner. 
Here you can see the followers of Leader A (in the middle of the screen). The picture of Leader A is in the left corner. Place the picture of Leader A on a position on the screen, which you think best represents the relationship to his followers (use the mouse to move the leader picture). Press the "continue" button once you have placed the picture.

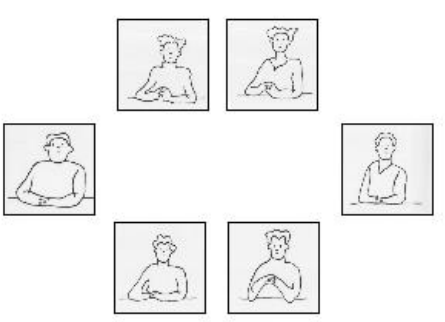

Note. The original text-material used in Study $3 \mathrm{~b}$ was in Dutch. Please note that the drawings are not the original ones, because of copyright reasons. The drawings, however, are similar to the ones used in the original Study $3 \mathrm{~b}$. The original materials can be obtained from the first author. 


\section{Publications in the ERIM Report Series Research* in Management}

\section{ERIM Research Program: "Organizing for Performance"}

2007

Leadership Behaviour and Upward Feedback: Findings From a Longitudinal Intervention

Dirk van Dierendonck, Clare Haynes, Carol Borrill and Chris Stride

ERS-2007-003-ORG

http://hdl.handle.net/1765/8579

The Clean Development Mechanism: Institutionalizing New Power Relations

Bettina B.F. Wittneben

ERS-2007-004-ORG

http://hdl.handle.net/1765/8582

How Today's Consumers Perceive Tomorrow's Smart Products

Serge A. Rijsdijk and Erik Jan Hultink

ERS-2007-005-ORG

http://hdl.handle.net/1765/8984

Product Intelligence: Its Conceptualization, Measurement and Impact on Consumer Satisfaction

Serge A. Rijsdijk, Erik Jan Hultink and Adamantios Diamantopoulos

ERS-2007-006-ORG

http://hdl.handle.net/1765/8580

Testing the Strength of the Iron Cage: A Meta-Analysis of Neo-Institutional Theory

Pursey P.M.A.R. Heugens and Michel Lander

ERS-2007-007-ORG

http://hdl.handle.net/1765/8581

Export Orientation among New Ventures and Economic Growth

S. Jolanda A. Hessels and André van Stel

ERS-2007-008-ORG

http://hdl.handle.net/1765/8583

Allocation and Productivity of Time in New Ventures of Female and Male Entrepreneurs

Ingrid Verheul, Martin Carree and Roy Thurik

ERS-2007-009-ORG

http://hdl.handle.net/1765/8989

Cooperating if one's Goals are Collective-Based: Social Identification Effects in Social Dilemmas as a Function of Goal-Transformation David De Cremer, Daan van Knippenberg, Eric van Dijk and Esther van Leeuwen

ERS-2007-010-ORG

http://hdl.handle.net/1765/9041

Unfit to Learn? How Long View Organizations Adapt to Environmental Jolts

Pursey P. M. A. R. Heugens and Stelios C. Zyglidopoulos

ERS-2007-014-ORG

http://hdl.handle.net/1765/9404

Going, Going, Gone. Innovation and Exit in Manufacturing Firms

Elena Cefis and Orietta Marsili

ERS-2007-015-ORG 
High in the Hierarchy: How Vertical Location and Judgments of Leaders' Power are Interrelated Steffen R. Giessner and Thomas W. Schubert

ERS-2007-021-ORG

* A complete overview of the ERIM Report Series Research in Management: https://ep.eur.n//handle/1765/1

ERIM Research Programs:

LIS Business Processes, Logistics and Information Systems

ORG Organizing for Performance

MKT Marketing

F\&A Finance and Accounting

STR Strategy and Entrepreneurship 